\title{
Planejamento estrutural, desenvolvimento e análise de propriedades farmacocinéticas in silico de análogos do ácido salicílico para fins cosméticos
}

\author{
Rômulo Barros dos Santos ${ }^{1}$, Wendy Fernanda Sales do Vale ${ }^{2}$ e \\ Charllyton Luís Sena da Costa ${ }^{3}$
}

1 Discente do Curso de Bacharelado em Farmácia da Faculdade Santo Agostinho. Aluno Pesquisador do Núcleo de Iniciação à Pesquisa (NIP) da Faculdade Santo Agostinho, Brasil. E-mail: romulofar.95@gmail.com

2 Discente do Curso de Bacharelado em Farmácia da Faculdade Santo Agostinho. Aluna Pesquisadora do Núcleo de Iniciação à Pesquisa (NIP) da Faculdade Santo Agostinho, Brasil. E-mail: wendysales123@gmail.com

3 Doutor em Biotecnologia pela Renorbio. Docente e Coordenador do Curso de Bacharelado em Farmácia da Faculdade Santo Agostinho. Pesquisador do Núcleo de Iniciação à Pesquisa (NIP) da Faculdade Santo Agostinho (FSA), Brasil. E-mail: charllyton@gmail.com

RESUMO: Formulações cosméticas contendo hidroxi-ácidos (HAs) têm sido utilizadas na prática clínica por décadas para tratar uma variedade de condições de pele. O ácido salicílico, representante mais proeminente utilizado nesta classe, tem sido usado como esfoliante ou agente queratolítico, e no tratamento de linhas finas e rugas, na pigmentação da pele, caspa, dermatite seborreica, acne e para melhorar a aparência estética geral da pele. Diante disto, a presente pesquisa objetivou desenvolver análogos in silico de ácido salicílico para fins cosméticos, através da caracterização quanto às suas propriedades físicoquímicas, farmacocinéticas e farmacodinâmicas dos fármacos desenvolvidos. Os compostos desenvolvidos, assim como as moléculas referências, foram analisados nos softwares ACD/ChemSketch, MarvinSketch versão 5.9.0, PreADMET versão 2.0 e SpartanStudent for Universities. Dentre as substâncias utilizadas para incrementação molecular tiveram maior relevância o ácido retinóico e seus derivados retinol e retinal, além da utilização da ureia, serina, ácido láctico, ácido palmítico, ácido recinoléico e a norbixina. O planejamento molecular possibilitou o desenvolvimento de 35 moléculas denominadas RWC. Desta forma, foi possível verificar através das análises realizadas que a grande maioria das moléculas criadas teve similaridade às moléculas do grupo dos retinóides o que implica dizer que estas apresentaram excelentes resultados tendo em vista o objetivo do referido estudo.

Palavras - chaves: Desenvolvimento molecular; Ácido salicílico; Análogos.

Structural planning, development and analysis of in silico pharmacokinetic properties of salicylic acid analogues for cosmetic purposes

ABSTRACT: Cosmetic formulations containing hydroxy acids (HAs) have been used in clinical practice for decades to treat a variety of skin conditions. Salicylic acid, the most prominent representative used in this class, has been used as an exfoliant or keratolytic agent, and in the treatment of fine lines and wrinkles, skin pigmentation, dandruff, seborrheic dermatitis, acne and to improve the general aesthetic appearance of the skin. In view of this, the present research aimed to develop in silico analogs of salicylic acid for cosmetic purposes, through the characterization of its physicochemical, pharmacokinetic and pharmacodynamic properties of the drugs developed. The developed compounds, as well as the reference molecules, were analyzed in ACD / ChemSketch software's, MarvinSketch version 5.9.0, PreADMET version 2.0 and SpartanStudent for Universities. Among the substances used for molecular increase, retinoic acid and its retinol and retinal derivatives were more relevant, besides the use of urea, serine, lactic acid, palmitic acid, recinolytic acid and norbixin. The molecular planning allowed the development of 35 molecules called RWC. Thus, it was possible to verify through the analysis that the great majority of the molecules created had similarity to the molecules of the retinoid group, which implies that these presented excellent results in view of the objective of said study.

Keywords: Molecular development; Salicylic acid; Analogues. 


\section{INTRODUÇÃO}

Formulações cosméticas contendo hidroxi-ácidos (HAs) têm sido utilizadas na prática clínica por décadas para tratar uma variedade de condições de pele. O representante mais proeminente utilizado nesta classe através de uma variedade de produtos para uso diário por longos períodos de tempo é o ácido salicílico (AS). Um dos efeitos benéficos mais citados dos HAs é a melhora relatada da pele fotoenvelhecida. Estas melhorias foram medidas como diminuições de rugosidade, descoloração, queratoses solares e pigmentação global e também como densidade aumentada de colágeno e qualidade melhorada de fibras elásticas (KORNHAUSER; COELHO; HEARING, 2010).

$\mathrm{O}$ ácido salicílico é um potente agente tópico e tem sido utilizado para tratar uma ampla variedade de desordens da pele, especialmente a acne. Ele tem sido usado como esfoliante ou agente queratolítico, e no tratamento de linhas finas e rugas, na pigmentação da pele, caspa, dermatite seborreica, acne, infecções micose, psoríase, calos, ictiose, verrugas, e para reduzir a hiperpigmentação (por exemplo, em geral manchas e sardas), e para melhorar a aparência estética geral da pele. No entanto, sua utilização em alguns indivíduos pode resultar em irritação e secagem excessiva da pele (SHIN; HU; XI, 2014).

A pesquisa realizada por Shin, $\mathrm{Hu}$ e $\mathrm{Xi}$ (2014) possibilitou o desenvolvimento, através de uma modificação molecular, de um dímero de ácido salicílico que evidenciou ser um estimulador potente de calicreína 5 (KLK5) e, assim, ajudando no melhoramento do aspecto estético da pele, no tratamento intrínseco de sinais de envelhecimento e foto-envelhecimento da pele, na hiperpigmentação cutânea e doenças de pele, tais como acne e manchas.

A modificação de moléculas é uma ferramenta bastante importante para a descoberta de novos fármacos que tenham efeito superior ao protótipo e garantam que sua eficácia é superior aos efeitos indesejáveis já apresentados pela molécula referência. $O$ planejamento e desenvolvimento desses novos fármacos é uma área da Química Farmacêutica Medicinal, ciência que engloba inovação, descoberta, síntese ou modificação molecular, extração, isolamento, identificação de substâncias bioativas, bem como suas respectivas relações entre estrutura química e atividade biológica (GUIDO; ANDRICOPULO; OLIVA, 2010).

De acordo com Kapetanovic (2009), o uso de técnicas computacionais no desenvolvimento e descoberta de fármacos está rapidamente ganhando popularidade, implementação e apreciação. Diferentes termos estão sendo aplicados a essa área, incluindo a concepção de fármaco assistida por computador (CADD), desenho de fármacos computacionais, design molecular assistido por computador (CAMD), modelagem molecular assistida por computador (CAMM). O papel das técnicas computacionais inclui: (i) uso do poder de computação para agilizar o processo de descoberta e desenvolvimento de medicamentos; (ii) alavancagem de informações químicas e biológicas das substâncias e (iii) desenho de filtros in silico para eliminar compostos com propriedades indesejáveis.

Para o desenvolvimento de um fármaco torna-se necessário o conhecimento amplo das propriedades físico-químicas, farmacocinéticas e farmacodinâmicas para que seus grupos funcionais favoreçam sua complementariedade bioquímica com o sítio de 
Planejamento estrutural, desenvolvimento e análise de propriedades farmacocinéticas do ácido salicílico para fins cosméticos105

ligação. As interações de um fármaco com seu receptor biológico são determinadas pelas forças intermoleculares, ou seja, são dependentes da sua lipofilicidade, polaridade e atividade eletrostática; Assim sendo, substâncias que apresentam propriedades terapêuticas, ao interagirem com um receptor orgânico devem possuir uma conformação tridimensional de forma que as disposições de seus grupos funcionais favoreçam sua complementariedade ao sítio de ligação (TECHIO; BELO, 2012).

Diante do explícito, a presente pesquisa objetivou desenvolver análogos in silico de ácido salicílico para fins cosméticos, através da caracterização quanto às suas propriedades físico-químicas, farmacocinéticas e farmacodinâmicas dos fármacos desenvolvidos.

\section{METODOLOGIA}

\subsection{Caracterização do estudo}

A pesquisa é enquadrada como do tipo experimental, explicativa com abordagem quantitativa, baseado na concepção de desenvolvimento de uma nova molécula a partir de um protótipo (ácido salicílico) no intuito de melhorar seus parâmetros farmacocinéticos por meio da química farmacêutica computacional.

\subsection{Procedimento de coleta de dados}

Os compostos desenvolvidos, assim como as moléculas referências, foram analisados nos softwares ACD/Chem- Sketch, MarvinSketch, PreADMET e Spartan Student for Universities. No processo de modelagem molecular, substâncias com características farmacológicas conhecidas foram incremen- tadas ao ácido salicílico em diferentes conformações, na tentativa de obter fármacos com propriedades semelhantes e/ou mais eficazes que o de referência.

\subsubsection{ChemSketch e MarvinSketch}

Na primeira etapa do estudo, a sequência de atividades foram realizadas no programa ChemSketch: (i) desenho das moléculas, (ii) arquivamento, (iii) otimização visualização da molécula na sua aproximação do real através da imagem 3D, (iv) exportação - mol e (v) análises físico - químicas no programa MarvinSketch.

\subsubsection{PreADMET - Farmacocinética}

Através do programa PreADMET foram realizadas as análises farmacocinéticas e toxicológicas das moléculas. A farmacocinética, de maneira geral, utiliza metodologia matemática para descrever as variações no tempo dos processos de administração, absorção, distribuição, biotransformação e eliminação das drogas (ADMET), além de delimitar variáveis básicas no estudo entre concentração das drogas nos diferentes fluidos e tecidos e sua excreção no organismo. Dentre os parâmetros disponíveis no programa, tiveram maior significância durante as análises: $\mathrm{CaCo} 2$ (taxa de absorção), HIA (taxa de absorção intestinal humana), MDCK (excreção), Plasma-Protein (distribuição) e Skin (velocidade em que o fármaco atravessa a pele).

\subsubsection{Spartan Student for Universities}

O Spartan Student foi utilizado para determinar o espaço conformacional de cada composto, a fim de determinar os confór- 
meros de energia mais estáveis e o de menor energia. Para essa análise duas características foram avaliadas:

a) Equilibrium Conformer: responsável por encontrar geometrias de equilíbrio adicionais, através do movimento de cada átomo em passos espaciais bastante grandes e exibir a conformação mais energeticamente favorável.

b) Equilibrium Geometry - Hartree Fock: este cálculo primeiro aperfeiçoa a geometria da molécula e depois calcula a energia e as quantidades termodinâmicas. Esse processo envolve mover cada átomo individual na molécula em pequenos passos em todas as direções para testar se a energia aumenta ou diminui. No caso de um aumento de energia o programa sabe que o estado inicial era mais energeticamente favorável, e se a energia diminui a nova confirmação molecular é mais pertinente energeticamente. No final, a confirmação molecular com a menor energia é usada nos cálculos finais.

\subsection{Análise dos dados}

Os dados foram tratados estatisticamente por meio de estatística descritiva (média, desvio padrão, frequências) e estatística multivariada (Análise de Componentes Principais, Análise Discriminante e Análise de Agrupamento Hierárquico) para o tratamento completo do conjunto de dados obtidos e ferramenta de seleção das moléculas a partir das propriedades analisadas.

\section{RESULTADOS E DISCUSSÃO}

\subsection{Desenho e Visualização Tridimensional das Moléculas}

Durante o planejamento estrutural das moléculas análogas, o ácido salicílico (Figura 1) - como a principal substância utilizada nas preparações cosméticas - foi estabelecida como protótipo (molécula base), uma vez que todas as modificações moleculares foram realizadas com base em sua estrutura original. Dentre as substâncias utilizadas para incrementação molecular tiveram maior relevância o ácido retinóico (Figura 2) e seus derivados retinol (Figura 3) e retinal (Figura 4), além da utilização da ureia, serina, ácido láctico, ácido palmítico, ácido recinoléico e a norbixina, uma vez que essa incrementação foi realizada na carbonila do ácido salicílico e posições orto, meta e para do anel aromático da molécula. O planejamento molecular possibilitou o desenvolvimento de 32 moléculas denominadas RWC.

Figura 1. Ácido salicílico Figure 1. Salicylic acid

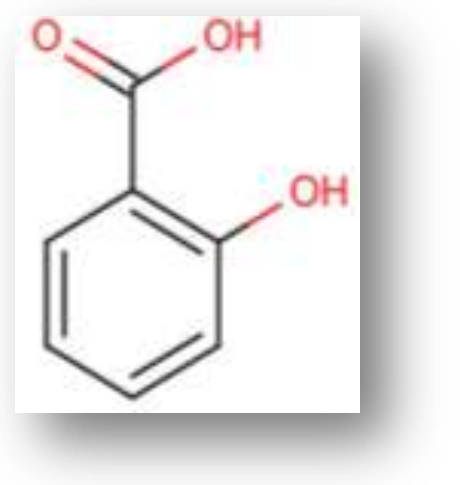

Figura 2. Ácido retinóico Figure 2. Retinoic acid

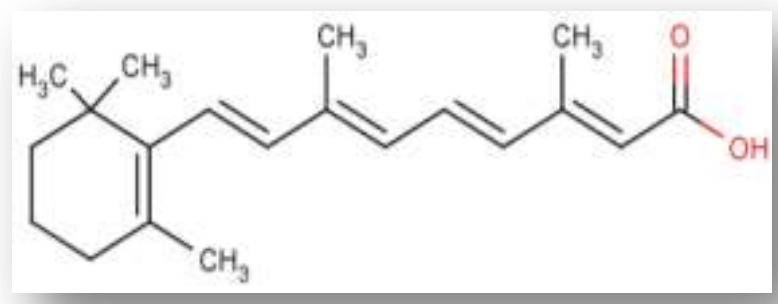


Figura 3. Retinol

Figure 3. Retinol

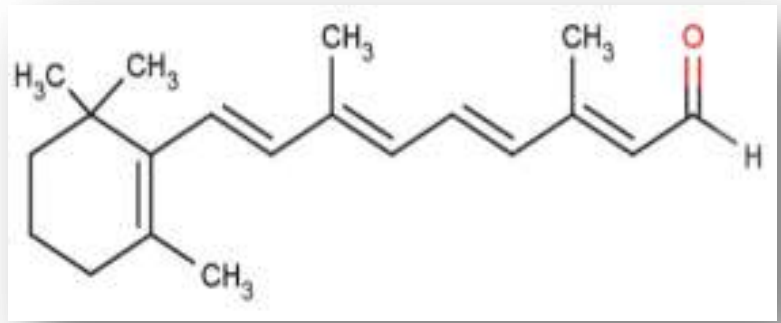

Figura 4. Retinal

Figure 4 - Retinal

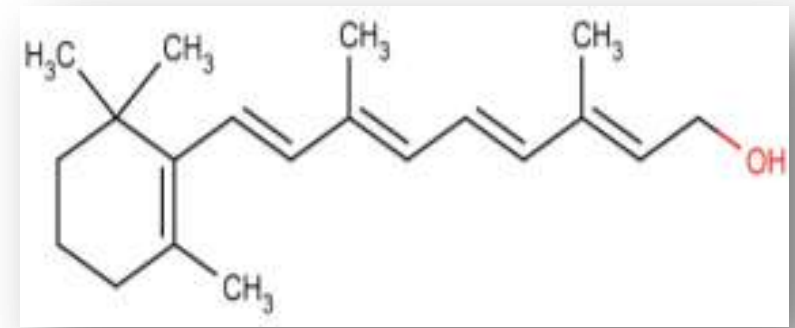

De acordo com a IUPAC, modelagem molecular é a investigação das estruturas e das propriedades moleculares pelo uso de química computacional e técnicas de visualização gráfica, visando fornecer uma representação tridimensional, sob um dado conjunto de circunstâncias. O planejamento de fármacos auxiliado por computador (CADD "Computer-Assisted Drug Design") é descrito em diversas páginas da internet e auxilia, com tutoriais, a investigação das interações químicas de um ligante com o seu receptor e exploração dos fatores estruturais relacionados ao efeito biológico.

O programa ChemSketch é uma ferramenta de desenho de moléculas bidimensionais. Esse programa possibilitou a elaboração de figuras com qualidade e exatidão desejadas, facilitando o trabalho de documentação e comunicação científica. A visualização tridimensional dos fármacos como etapa primordial para visualização das substâncias próxima do real foi realizada através da construção das ligações, passo a passo, no programa, observando as informações sobre comprimento e ângulo de ligação. Paralelamente, foram realizadas conversões de moléculas desenhadas para o modelo tridimensional em ACD/3D Viewer, em uma diversidade de formatos, como arame, esferas e cilindro, cilindro e "spacefilling", como exemplificado para o ácido salicílico (Figura $5)$.

Figura 5. Diferentes representações do ácido salicílico em ACD/3DViewer, (5a) arame, (5b) cilindro e esfera, (5c) cilindro e (5d) "space filling" (ChemSketch).

Figure 5. Different representations of salicylic acid in ACD / 3DViewer, (5a) wire, (5b) cylinder and sphere, (5c) cylinder and (5d) space filling (ChemSketch).

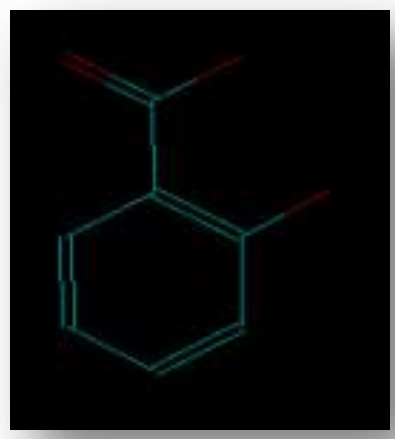

(5a)

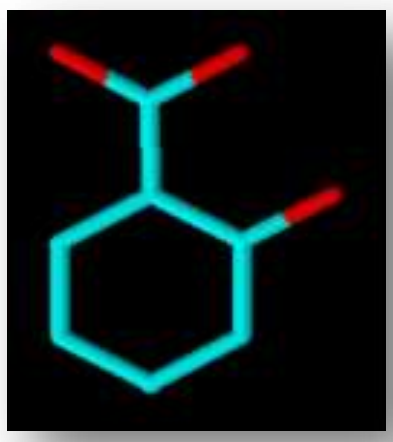

(5c)

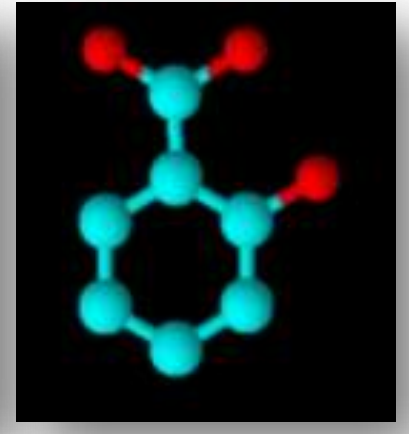

(5b)

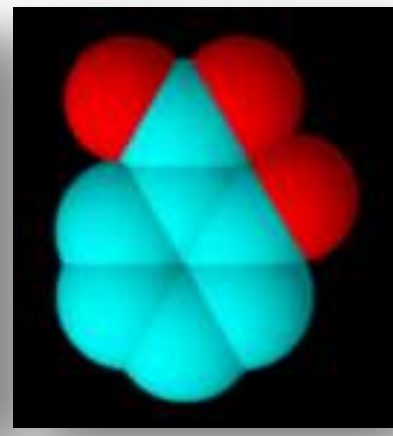

$(5 d)$
As moléculas desenhadas de forma tridimensional não estão, necessariamente, na conformação mais estável. Durante a geração de uma determinada estrutura, ocorrem distorções na molécula, com formação desfavorável de comprimentos e 
ângulos de ligações e ângulos diédricos. Átomos não ligados também interagem em uma mesma região do espaço e provocam repulsão estérica e eletrostática. Para corrigir estas distorções, as moléculas são otimizadas pelo processo de minimização de energia, a partir de dois modelos matemáticos disponíveis no programa Spartan Student: (i) equilibrium conformer e (ii) equilibrium geometry - hartree - fock. Interações não previsíveis, relacionadas à sobreposição de orbital molecular, distribuição de densidade eletrônica ou interferências estéricas são solucionados no programa. A minimização de energia e a análise conformacional são usadas interativamente para otimizar a geometria de uma molécula, como mostrado na Figura 6.

Figura 6. Otimização das moléculas no Programa Spartan Student, (6a) ácido salicílico, (6b) ácido retinóico.

Figure 6. Optimization of the molecules in the Spartan Student Program, (6a) salicylic acid, (6b) retinoic acid.

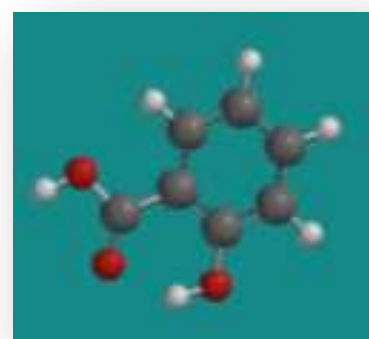

(6a)

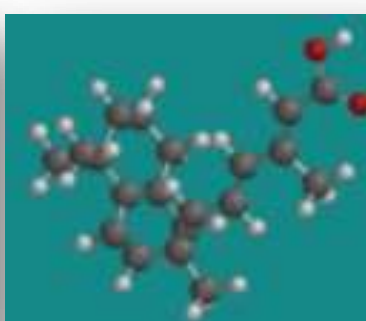

(6b)

\subsection{Planejamento Estrutural e Análises Pa- ramétricas dos Fármacos}

O ponto chave para o desenvolvimento de novas moléculas à base do protótipo ácido salicílico - é considerável pelo fato da molécula ter propriedades queratolíticas (esfoliantes), porém, não tem potência suficiente para atuar como agente de peeling, em virtude de sua ação superficial sobre a pele. A base do planejamento estrutural de novas moléculas a partir da modificação molecular contempla o desenvolvimento de substâncias que tenham aplicação tópica mais profunda, o que significa que parâmetros farmacocinéticos para essas moléculas são padrões críticos e necessários.

Parâmetros como $\mathrm{MDCK}, \mathrm{CACO}_{2}$, SkinPermeability, HIA e Plasma-Pro-tein foram analisados, por serem indicativos no processo em que o fármaco percorre o organismo, denominado farmacocinética (absorção, distribuição, metabolização e excreção - ADME) e significam respectivamente excreção, taxa de absorção, velocidade em que o fármaco atravessa a pele, taxa de absorção intestinal humana e distribuição. Esses parâmetros foram obtidos e analisados nos programas PreADMET e Spartan Student.

Como primeiro passo, foi verificado como as moléculas referências isoladamente (ácido salićlico, ácido mandélico, salsalate, ácido retinóico, retinol e retinal) se comportaram diante das variáveis analisadas no decorrer do trabalho, a fim de possibilitar a identificação de quais parâmetros melhor descrevem essas moléculas e como as novas substâncias devem se comportar para alcançar o efeito desejável.

Foi realizada uma Análise de Componentes Principais (ACP), que dá certa orientação do desempenho das moléculas de referência quanto aos parâmetros farmacocinéticos e qual a contribuição de cada variável para o comportamento das observações, diante de resultados multifatorial.

Ao realizar a análise (Gráfico 1 ), o resultado é uma Biplot dos eixos (F1 e F2), de forma que estabelece como as variantes, de acordo com os dados que foram expostos, reagem. 0 eixo principal explica $69,43 \%$ das variações no comportamento das molécu- 
Planejamento estrutural, desenvolvimento e análise de propriedades farmacocinéticas do ácido salicílico para fins cosméticos109

las, o que implica que quanto mais próximas do eixo principal, maior é a variação do parâmetro. Essa biplot estabelece a seguinte variação em ordem decrescente: HIA > Plasma-Protein $>$ Skin-Permeability $>\mathrm{CACO}_{2}$ $>$ MDCK. Verifica-se que o MDCK variou de forma oposta às demais variáveis, porém, apesar de estar correlacionado negativamente, indica que enquanto o HIA aumenta o MDCK diminui.

Gráfico 1. Análise de Componentes Principais (ACP) - Moléculas de referência com dados farmacocinéticos.

Graph 1. Principal Component Analysis (PCA) - Reference molecules with pharmacokinetic data.

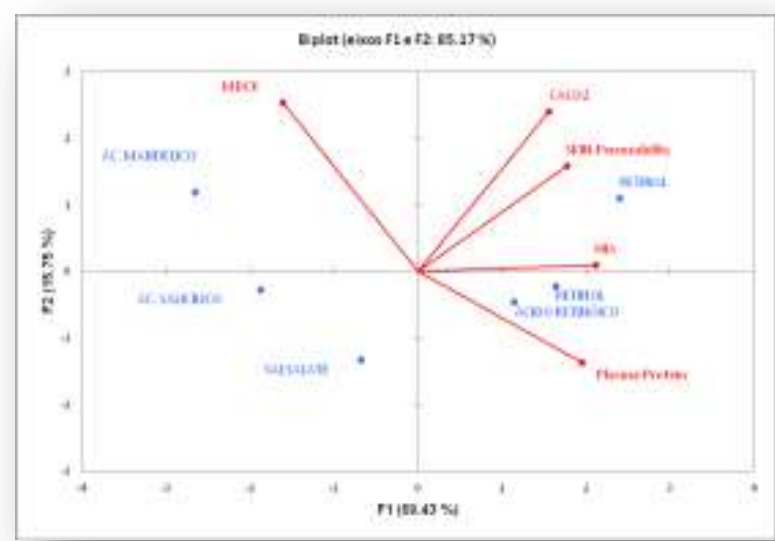

Fonte: Próprios Pesquisadores

Considerando os parâmetros farmacocinéticos, as moléculas se agrupam em duas grandes regiões opostas: uma região que agrupa moléculas da classe dos retinóides (direita) e uma região que agrupa moléculas da classe dos salicilatos (esquerda). Sabendo que as moléculas do grupo dos retinóides possuem uma boa penetração cutânea e o grupo dos salicilatos tem uma baixa penetração, verifica-se que os parâmetros de absorção direta (HIA e Skin-Permeability) definem mais o comportamento do acido retinóico, retinol e retinal. Dessa forma, para que se obtenha uma possível potência de absorção tópica, as moléculas deste es- tudo precisam ter características semelhantes da classe que melhor se comportou diante dos parâmetros de absorção cutânea, em vista que essa variável foi responsável pela separação dos dois grupos.

No grupo dos salicilatos, as moléculas Salsalate e Ácido mandélico referem-se a duas moléculas desenvolvidas a partir do ácido salićlico. $O$ salsalate foi desenvolvido no ano de 2016 por Shin, Hu e Xi, e o dímero desenvolvido mostrou-se benéfico no tratamento intrínseco de sinais de envelhecimento e foto-envelhecimento da pele. Por outro lado o Ácido mandélico foi desenvolvido no ano de 2015 por Kapuscinska e Nowak. As duas moléculas mostram-se agentes suaves de esfoliação.

O Gráfico 2, assim como o Gráfico 1, diz respeito à análise de componentes principais (ACP), porém, leva em consideração não só as moléculas de referência, mas, também, a todas as moléculas desenvolvidas durante o planejamento estrutural.

Como discutido no Gráfico 1, os parâmetros de absorção direta definem mais o comportamento do ácido retinóico, retinal e retinol. Isso significa que para que tenham uma absorção tópica ideal, as novas moléculas devem ficar próximas das moléculas do grupo dos retinóides e não das moléculas do grupo dos salicilatos como discutido anteriormente.

Desta forma, é possível observar no Gráfico 2, que a grande maioria das moléculas desenvolvidas ficaram próximas das moléculas de referência que apresentam melhor permeabilidade. Visto que, apesar de algumas moléculas não serem análogas do grupo dos retinóides, mesmo assim, mostramse semelhantes no que diz respeito às características farmacocinéticas deste grupo. Porém algumas moléculas apresentaram-se 
semelhantes ao grupo dos salicilatos (RWC 01 a RWC 09), o que indica que estas poderão ter dificuldades na sua absorção.

Gráfico 2. Análise de Componentes Principais de todas as moléculas com dados farmacocinéticos.

Graph 2. Principal Component Analysis of all molecules with pharmacokinetic data.

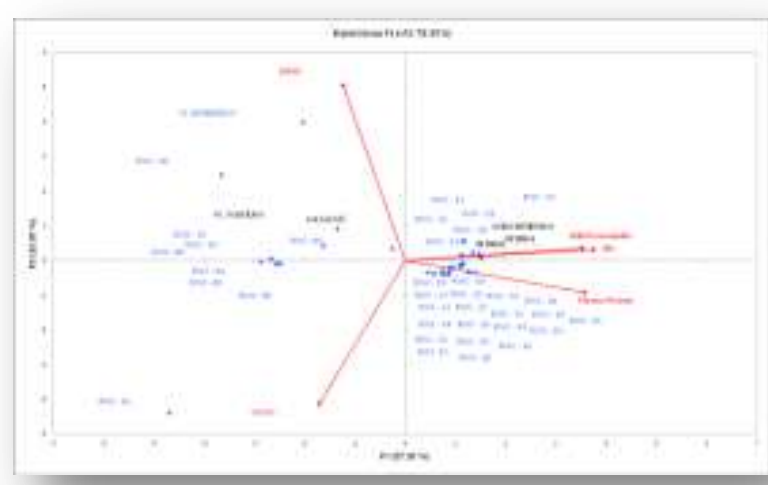

Fonte: Próprios Pesquisadores

O Dendograma (Gráfico 3) diferentemente do biplot, é um método de classificação para enquadrar as moléculas com base em suas semelhanças através de um agrupamento hierárquico. Considerando apenas os dados farmacocinéticos, o dendograma permite a visualização das moléculas com base em suas similaridades, levando-se em consideração todas as variáveis analisadas. Hierarquicamente as moléculas são enquadradas em 5 grandes categorias (entre $94 \mathrm{e}$ 95\%) e estas são distribuídas em subcategorias (97 a 100\%), verificando-se que à medida em que se aproxima da base, a equivalência entre os fármacos se aproxima de $100 \%$.

É importante ressaltar que do ponto de vista farmacocinético, as moléculas RWC 30, RWC 31 e RWC 32 que estão próximas ao ácido retinóico, provavelmente possuem as características mais adequadas com relação à penetração cutânea, uma vez que a aproximação de equivalência de aproxima- damente $100 \%$ confirma todas as análises realizadas anteriormente. Vale destacar também a molécula RWC 02, já que a mesma pertence a uma categoria isolada, o que indica diferença de todas as outras moléculas. Mostram-se pouco similares às moléculas pertencentes ao grupo do salsalate e o grupamento de moléculas RWC 03, RWC 04, RWC 05, RWC 07, RWC 08 e RWC 09.

Gráfico 3. Análise de agrupamento hierárquico de todas as moléculas com base nos dados farmacocinéticos.

Graph 3. Hierarchical cluster analysis of all molecules based on pharmacokinetic data.

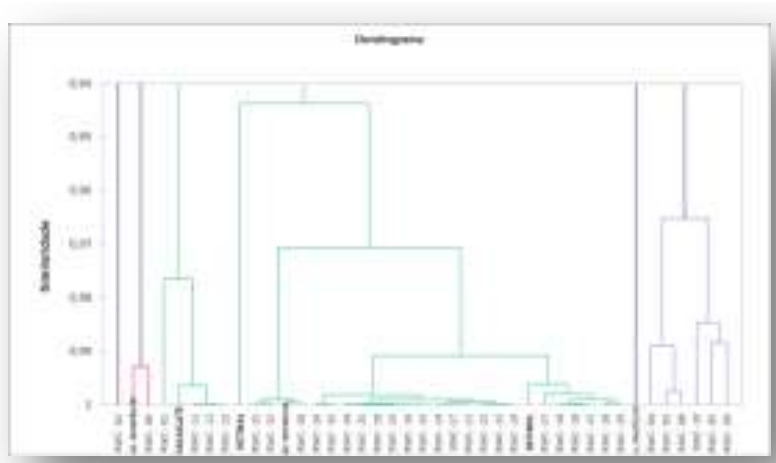

Fonte: Próprios Pesquisadores

O Gráfico 4 representa uma análise discriminante das moléculas considerando a origem e todas as variáveis utilizadas, ou seja, todas as moléculas desenvolvidas foram agrupadas, levando em consideração as propriedades farmacocinéticas e a similaridade com as moléculas que foram utilizadas, tais como ácido salicílico, ácido retinóico, retinal, retinol, serina, ácido láctico, ácido palmítico, ácido recinoléico e norbixina. 
Planejamento estrutural, desenvolvimento e análise de propriedades farmacocinéticas do ácido salicílico para fins cosméticos111

Gráfico 4. Análise discriminante das moléculas considerando a origem (molécula na modificação) e todas as variáveis utilizadas.

Graph 4. Discriminant analysis of the molecules considering the origin (molecule in the modification) and all the variables used.

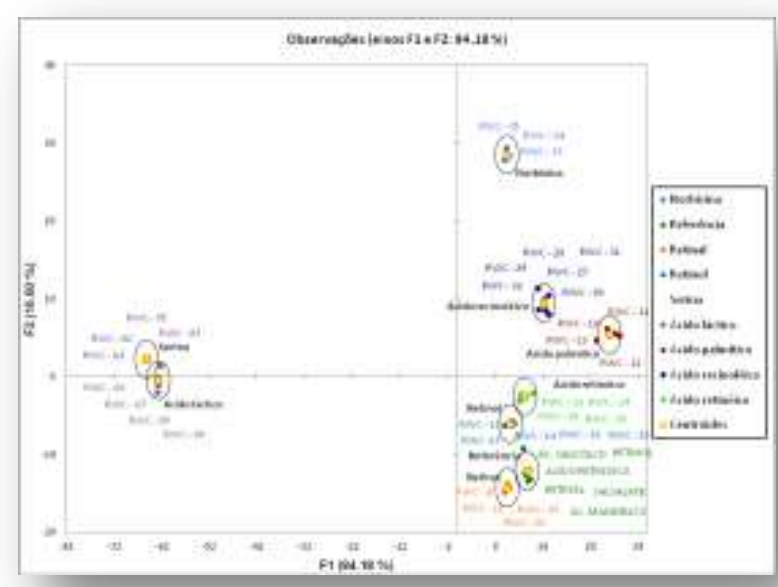

Fonte: Próprios Pesquisadores

\section{CONSIDERAÇÕES FINAIS}

Avanços científicos e tecnológicos na área de química farmacêutica têm proporcionado grandes oportunidades para o desenvolvimento de novas moléculas candidatas a fármacos em potencial. Deste modo, através da utilização de recursos de modificação molecular foi possível desenvolver 35 moléculas tendo como base principal o ácido salićlico, difusamente utilizado para uma grande variedade de problemas dermatológicos. Para que uma molécula aja de forma eficiente na pele, é necessário que esta apresente uma boa penetração cutânea, ou seja, tenha uma lipofilicidade adequada, porém sabe-se que as moléculas do grupo dos salicilatos são pouco permeáveis. Para que estes análogos fossem desenvolvidos foram incrementadas ao ácido salicílico várias moléculas com propriedades dermatológicas conhecidas, dentre a quais foram utilizadas o ácido retinóico, retinal, retinol, serina, ácido láctico, ácido palmítico, ácido recinoléico e norbixina. As moléculas de referência que obtiveram bons resulta- dos quanto às propriedades farmacocinéticas relacionadas a permeabilidade foram o ácido retinóico, retinal e retinol. Sabendose disso, foi possível verificar através das análises realizadas que a grande maioria das moléculas desenvolvidas tiveram similaridade às moléculas do grupo dos retinóides o que implica dizer que estas apresentaram excelentes resultados tendo em vista o objetivo do referido estudo.

\section{REFERÊNCIAS}

GUIDO, R.V.C.; ANDRICOPULO, A.D.; OLIVA, G. Planejamento de fármacos, biotecnologia e química medicinal: aplicações em doenças infecciosas. Estudos Avançados, v. 74, n. 70, p. 81-98, 2010.

KORNHAUSER, A.; COELHO, S.G.; HEARING, V.J. Applications of hydroxu acids: classification, mechanisms, and photoactivity. Clinical, Cosmetic and Investigational Dermatology, 2010:3, p. $135-142$.

KAPETANOVIC, I.M. Computer-aied drug Discovery and development (CADDD): in silico-chemico-biological approach. Chemico Biological Interactions, v. 171, n. 2, p. 165-176, jan. 2008.

KAPUSCINSKA, A.; NOWAK, I. Zastosowanie kwasow organicznych $w$ terapii tradziku i przebarwien skory. Postepy Hig Med Dosw, v. 69, p. 374-383, 2015.

SHIN, S.B,; HU, H.; XI, K., inventores; Avon Products, Inc., cessionário. Cosmetic use of salicylic acid derivatives. New York patent US 20160193127. 2016.

TECHIO, P.X.; BELO, M.A.A. Estrutura química e interação molecular farmacodinâmica entre salicilatos e oxicans. Enciclopédia biosfera, v. 8, n. 14, p. 1537-1560, 2012. 

access article distributed under the terms of the Creative Commons Attribution License, which permits unrestricted use, distribution, and reproduction in any medium, provided the original work is properly cited.

Artigo recebido em 09 de maio de 2017.

Avaliado em 19 de maio de 2017.

Aceito em 26 de maio de 2017.

Publicado em 18 de agosto de 2017.

\section{Como citar este artigo (ABNT):}

SANTOS, Rômulo Barros dos; VALE, Wendy Fernanda Sales do; COSTA, Charllyton Luís Sena da. Planejamento estrutural, desenvolvimento e análise de propriedades farmacocinéticas in silico de análogos do ácido salicílico para fins cosméticos. Estação Científica (UNIFAP), Macapá, v. 7, n. 1, p. 103-112, jan./abr. 2017. 